\title{
Investigating an Efficient and Accurate Protocol for Sampling Structures from Molecular Dynamics Simulations: A Close Look by Different Wavelet Families
}

\author{
Mateus Gonçalves ${ }^{1}$, Arismar Junior ${ }^{2}$, Elaine da Cunha ${ }^{3}$, and Teodorico Ramalho ${ }^{4}$ \\ ${ }^{1}$ Universidade Federal de Lavras \\ ${ }^{2} \mathrm{UEMG}$ \\ ${ }^{3}$ Federal Ubiversity of Lavras \\ ${ }^{4}$ UFLA
}

February 25, 2021

\begin{abstract}
Molecular Dynamics (MD) simulations are widely used to predict the behavior of molecular systems over time. However, one of the great challenges of MD simulations is how to treat the thousands of configurations obtained from calculations, since the number of the quantum calculations (QM) required for evaluating electronic parameters is too high and, sometimes, computationally impracticable. Thus, an efficient and accurate sampling protocol is essential for combining classical MD and QM calculations. In this article, based on the OWSCA methodology, 93 wavelet signals were analyzed in order to further refine the methodology and identify the best wavelet family for $[\mathrm{Fe}(\mathrm{H} 2 \mathrm{O}) 6] 2+$ and $[\mathrm{Mn}(\mathrm{H} 2 \mathrm{O}) 6] 2+$ complexes in solution. Our results point out that the bior1.3 was the best wavelet, values closest to the experimental data were obtained for both studied systems.
\end{abstract}

\section{Hosted file}

Aquino_Ramalho3.pdf available at https://authorea.com/users/398142/articles/510812investigating-an-efficient-and-accurate-protocol-for-sampling-structures-from-moleculardynamics-simulations-a-close-look-by-different-wavelet-families 